\title{
Apropiacionismo en el arte, la legitimidad de la imagen sustraída
}

\section{Art appropriationism, the legitimacy of the stolen image}

\author{
TIPO DE TRABAJO: Comunicación.
}

PALABRAS CLAVE

Apropiacionismo artístico, copia, collage, Ready-Made, pintura.

KEY WORDS

Artistic appropriationism, copy, collage, Ready-Made, painting.

RESUMEN

Este proyecto plantea el apropiacionismo en el arte como una estrategia usada a lo largo de toda la Historia del Arte, y en la actualidad podría ser un recurso que actúa casi como respuesta a la saturación de imágenes que inundan las sociedades globales. En primer lugar, reflexionamos ¿Qué sentido tiene recurrir a algo ya hecho para crear?, ¿Es menos original basarse en otras obras? Con ello nos planteamos si hay alguna creación totalmente original en la que el autor no haya partido de otros referentes. Por otra parte, el apropiacionismo lleva implícita una crítica al concepto tradicional de autoría, si bien es cierto que superadas estas incertidumbres iniciales, tomamos esta práctica como un recurso completamente validado. De manera que analizamos como el hecho de adueñarse de imágenes visibles y reconocibles es un acicate óptimo para desarrollar un nuevo concepto. El apropiacionismo abordado por tanto como una vía de comunicación y de enriquecimiento en los discursos artísticos, que permite reflexionar sobre el concepto de imagen. Los artistas en un proceso que se basa en; percibir, identificar, interpretar y significar, se adueñan de imágenes pertenecientes al imaginario colectivo y consiguen generar nuevas lecturas. En ese sentido logran extrapolar el significado original a la actualidad, dotándolo de otra narrativa, que trata de dar respuestas a problemáticas actuales. Hacemos una revisión del apropiacionismo a lo largo de la Historia del Arte. Y además se analiza la obra de artistas como Benjamín Domínguez, Eisen Bernard Bernardo y el Equipo Crónica que ven en él una oportunidad para ampliar su propia técnica: una herramienta de trabajo y de estudio que explore las posibilidades de una misma idea/imagen, de manera que la obra conocida sirva de medio para el desarrollo creativo.

\section{ABSTRACT}

This project proposes the art appropriationism as a strategy used throughout the entire history of art, and now it could be a resource that acts almost as a response to the saturation of images that overwhelms the global societies. Firstly, we wonder whether the artworks based on other creations are less original. We resort to something already made to create: what is the point of it? Is there a completely original creation in which the author has not drawn his work from other references? Appropriationism implies a critique to the traditional concept of authorship, even though once we overcome these initial uncertainties, we take this practice as a fully validated resource. With this in mind we analyze how the fact of appropriating visible and recognizable images is an excellent incentive to develop a new concept. Appropriationism, as a way of communication and enrichment in the artistic discourses, allows us to reflect on the concept of image. Artists, in a process that is based on: perceive, identify, interpret and mean, take over images belonging to our collective worldview and they generate new readings. In that sense they extrapolate the original meaning to the present day, providing it with another narrative that responds to current issues. Finally, we undertake a review of the appropriationism throughout the history of art to put in value its ability to multiply ideas and enrich the artistic work. Besides that, we discuss the work of artists like Benjamín Domínguez, Eisen Bernard Bernardo and the Equipo Crónica who see an opportunity to expand their own technique: a study tool that explores the possibilities of the same idea/image, allowing the known work to be used as a medium for creative development. 


\section{CONTENIDO}

El ser humano, en las diferentes artes, siempre ha creado consciente o inconscientemente a partir de un referente en el que basarse, que le ha servido de motor para alcanzar nuevos contenidos. La forma más explícita de copia es el apropiacionismo, término que se emplea exclusivamente en arte para definir la tendencia a utilizar elementos ya existentes para la creación de una obra nueva. Según la definición publicada en la Kunzt Gallery: "Es el uso de imágenes u objetos pre-existentes que son escasamente o no transformados." (Ghesquière, 2019, párr. 1). Estos elementos pueden ser una parte, o el todo, de la obra de otro autor, objetos cotidianos o imágenes de la cultura popular. Es una cesión a modo de préstamo lícito, sin ánimo de lucro sino con fin artístico. En la que el artista deja claro su firme propósito de basarse en otra obra concreta para versionarla.

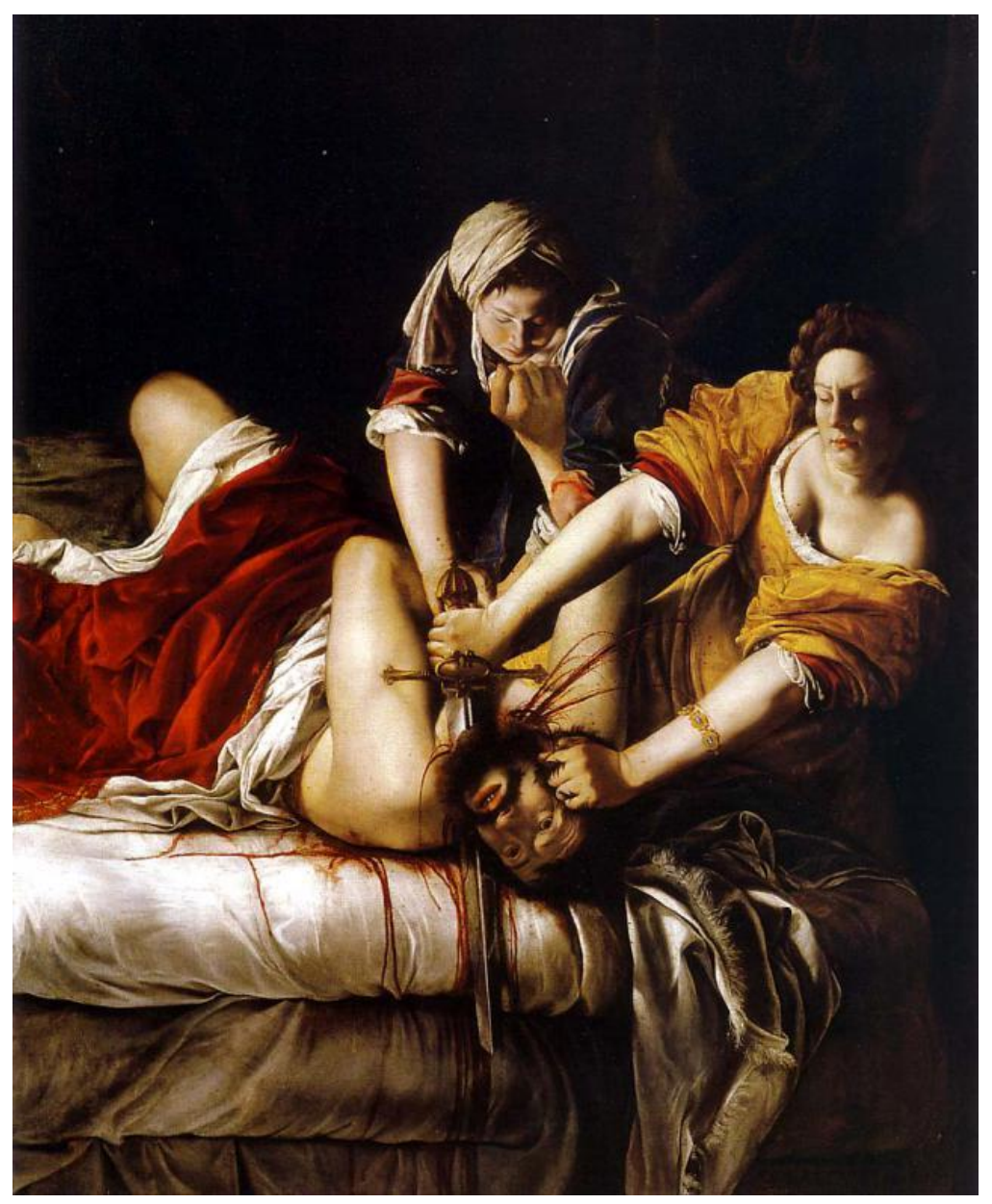

Figura 1. Judith decapitando a Holofernes. Artemisia Gentileschi. 1620. Extraída de Commons Wikipedia. Recuperado de https://commons.wikimedia.org/wiki/File:Gentileschi Artemisia Judith Beheading Holofernes Naples.jpg

A finales de los años setenta del siglo pasado, se acuñó el apropiacionismo a raíz de la exposición de Pictures de Douglas Crimp. Predecesor de esto fue el collage y Marcel Duchamp con la filosofía del Ready-Made y sus Objets Trouvés, es decir, objetos sacados de la realidad expuestos en un contexto artístico. No obstante, este proceso se remonta a la estatuaria clásica, pues las esculturas romanas eran copias de modelos helenos, así como en los cuadros de mitos clásicos y pasajes bíblicos del Barroco y Renacimiento, que los artistas versionaban introduciendo variaciones compositivas, como son El rapto de las Sabinas o Judit y Holofernes. De este último tenemos la versión de Caravaggio (Fig.2) y la de Artemisia (Fig.1), ella respeta a los personajes, pero acentúa la crudeza de la situación variando posturas y gestos. 


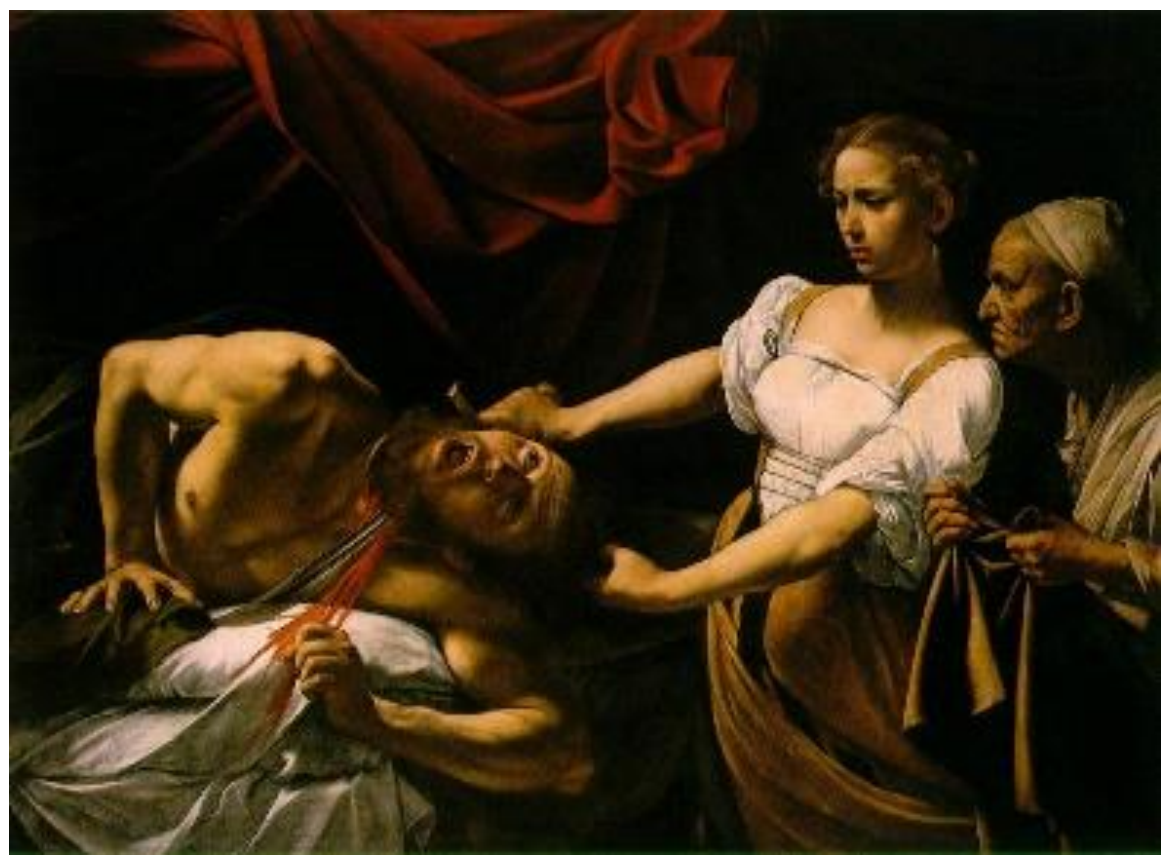

Figura 2. Judith y Holofernes. Caravaggio. 1589. Extraída de Commons Wikipedia. Recuperado de https://commons.wikimedia.org/wiki/File:Caravaggio Judith Beheading Holofernes.jpg

La copia es una práctica aceptada en la Historia del Arte, aunque hay cierto tabú en reconocerlo, porque aún tiene connotaciones negativas. De hecho, los artistas tienen que hacer malabares con el Copyright para demostrar su valía, por las connotaciones negativas que denota el apropiacionismo. Son conocidos los problemas que han tenido algunos artistas por apropiarse de obras ajenas. En 1964, Andy Warhol tuvo que llegar a un acuerdo económico con la fotógrafa Patricia Caulfield por usar sin autorización una imagen suya de un ramo de flores y haberla serigrafiado a gran escala. Richard Prince se vio sometido a una demanda por infracción de derechos de autor en 2015 al refotografiar y exponer en la galería Frieze de Nueva York un selfie de Ashley Salazar que ella había subido a Instagram (Aznar, 2016).

Por lo tanto, debemos tener claros los límites: ¿Cuál es la diferencia entre apropiacionismo y plagio? Solo hablaremos de plagio para referirnos a un acto ilegal, a un fraude artístico: el artista oculta la fuente en la que se ha inspirado, pretendiendo hacerse pasar íntegramente por su autor original. Un buen ejemplo de ello es el sevillano Francisco José García Lora. Este hombre llegó a convertirse en un experto falsificador de obras de Velázquez, Goya, Murillo, y Monet, ganando más de un millón de euros por un cuadro que le compró un coleccionista de arte. Acusado de estafa pictórica estuvo condenado a cuatro años y cinco meses de prisión, y pese a haber cumplido con la justicia, sus falsificaciones aún permanecen en el mercado (Campo, 2017).

Un apropiacionismo correcto posibilita el uso de obras de dominio público o que no estén protegidas por la propiedad intelectual, en el resto de casos su uso podría ser delicado. La Ley de Propiedad Intelectual de 1996 establece que el autor es el propietario de los derechos de imagen de sus obras. Luego, sus herederos mantienen esa condición durante los 70 años posteriores al 1 de enero del año siguiente al fallecimiento del creador (González, 2018). Siendo así, un acto apropiacionista si se identifica la obra de otro autor, en este caso se necesitaría su autorización o de aquellos que gestionen sus derechos de imagen.

El apropiacionismo empezó cuestionando los engranajes del sistema del arte. Como diría Walter Benjamín (citado por Vila-Matas, p. 124): "En nuestro tiempo la única obra realmente dotada de sentido, de sentido crítico, debería ser un collage de citas, fragmentos, ecos de otras obras." ¿Encontraríamos con ello la verdad absoluta?, como hicieron los cubistas al introducir el collage en los cuadros. También sirve para recontextualizar la obra "sustraída" a nuestro tiempo actual, encontrando relecturas contemporáneas y haciendo reflexionar sobre los cambios que experimenta la sociedad.

Cabe decir que las diferentes manifestaciones de apropiación que surgieron en sus orígenes, se acercaban bastante al concepto más puro de copia. Entre estas tipologías de representación próximas a la obra original tenemos: el Ready-Made, acuñado por Marcel Duchamp en 1915, la refotografía, técnica de fotografía sobre fotografía prácticamente sin alteración, el collage y la imitación pictórica. Este sería el orden progresivo según su grado de iconicidad o, lo que es lo mismo, grado de isomorfismo, es "la similitud de forma en 
Esgueva López, Victoria y Nicolau López, Nuria

Apropiacionismo en el arte, la legitimidad de la imagen sustraída

IV Congreso INTERNACIONAL DE INVESTIGACIÓN EN ARTES VISUALES ANIAV 2019

IMAGEN [N] VISIBLE

http://dx.doi.org/10.4995/ANIAV.2019.9094

relación a los referentes, es inverso a su grado de abstracción, dicho grado varía a lo largo de una amplia escala, la más conocida es la de Abraham Moles (1973)" (COSTA, 1992, p. 65).

Se repasan a continuación las tipologías antes citadas, en primer lugar, se sitúa por su alto grado de iconicidad el Ready-Made de los surrealistas, que con su significación irracional, consiguen realzar la dignificación de objetos vulgares que no necesitan ser pintados para ser arte. Esto nos conduce a la reflexión que lanzaron los surrealistas respecto al arte encontrado: ¿Quién decide qué es arte y qué no? En el Ready-Made los artistas no creaban de cero sus obras, sino que elegían objetos de la realidad. Los primeros Ready-Mades fueron de Marcel Duchamp: una rueda de bicicleta insertada en un taburete de 1913 y un urinario titulado Fontaine de 1915 firmado con el pseudónimo R. Mutt. Su Ready-Made más pictórico es L.H.O.O.Q. realizado en 1919, una postal con la reproducción de La Mona Lisa de Leonardo da Vinci a la que dibujó con lápiz un bigote y una perilla, su título podría traducirse como "está excitada". Los surrealistas se enamoraron de este concepto y realizarían posteriormente Ready-Mades más intervenidos y descontextualizados como El desayuno con pieles de Meret Oppenheim un kit de taza, plato y cuchara forrados de piel. Estas obras sacudieron los cimientos del arte y despertaron diversas críticas. En definitiva, configuraron un nuevo planteamiento en el arte de la modernidad.

En segundo lugar, la técnica de refotografia. En 1977 el teórico de arte Douglas Crimp organizó una exposición en el Artist Space de Nueva York titulada Pictures en la que Troy Brauntuch, Jack Golstein, Sherrie Levine, Robert Longo, Cindy Sherman y otros más se apropiaban de imágenes para sus obras. Fue entonces cuando la teoría apropiacionista tomó un nuevo impulso para cuestionar, más que la representación en sí, los mecanismos a través de las cuales ésta se codifica. Este nuevo discurso no critica la tiranía del significado, sino la tiranía del significante. Esto es, que los artistas que iniciaron esta etapa analizaban las imágenes que nos rodean (publicidad, cine, historia del arte...) para subvertir los estereotipos que encierran. Para ello empleaban la técnica de refotografía. Levine disloca el significado de la obra de Evans fotografiando reproducciones de sus obras en libros y usando títulos como After Walker Evans. Prince pone en evidencia el contenido ideológico de la marca Marlboro que intenta vincular la masculinidad de un cowboy con la de un americano medio.

La técnica del collage se originó por el concepto de similitud real con el referente al que representa, y por lo tanto también se apropia de imágenes que nos rodean, sin embargo, lo hace de manera parcial, a modo de retales que se pegan en el cuadro. Fue Braque el primero en incorporar fragmentos sacados de la realidad para representar esa propia realidad, eran etiquetas y retales de lo cotidiano, como evidencia el título de uno de sus primeros collages realizado en 1910, Le Quotidien (Violin and Pipe). Realmente este primer retal utilizado es una inscripción tipográfica, se trata pues de una apropiación de lo literario. Él explica su interés por traer aspectos de la vida cotidiana a sus composiciones tamizadas de análisis fragmentados, considerándolos "como parte del deseo de aproximarse lo más posible a cierto tipo de realidad" (Esgueva, 2011, p. 101). A partir de ahí, Picasso no pudo resistirse a experimentar con el Papier Collé. Les siguió Juan Gris, que en 1914 se dedicó a recortar de manera minuciosa y compleja confeccionando todo tipo de puzles en sus obras. Entre algunas prácticas surrealistas destacamos el collage fotográfico realizado con ilustraciones de libros que fue magistralmente cultivado por Max Ernst y que más tarde reanudó Magritte. El italiano Burri, en clave mucho más matérica, se servía de trapos, papeles y maderas quemadas, plásticos arrugados, chapas o sacos rotos. Pegaba, soldaba incluso cosía con un oficio burdo pero agudísimo: crea una iconografía del sufrimiento y la materia herida.

Posterior a estos movimientos, el imitador pictórico Mike Bidlo (1953) nos descubre otra rama de apropiación en esta línea. Este artista americano es un profesional de la mímesis. Hace réplicas exactas de los grandes artistas como Franz Kline, Klein o Picasso. Se adueña de su técnica, imita su estilo y titula sus creaciones negando al artista en el que se basa. Es el caso de Not Picasso, una serie que burla la originalidad en el arte, pues al espectador medio le resulta imposible distinguir las pinturas de esta serie de las de Picasso. No hablamos de un robo, ni de una falsificación, ni de una reproducción. Y es que no es un Picasso, no es un falso Picasso, no es una réplica de Picasso, es una obra original de Bildo.

Como referentes en la reinterpretación de clásicos estudiamos a cuatro autores que trabajan con diferentes métodos una apropiación que, en este caso, se aleja en gran medida de la obra original.

Benjamín Domínguez (1942-2016) nacido en Chihuahua (México), conocido como el pintor del dolor y el gozo. Vivió la crisis del arte mexicano y el empoderamiento del arte moderno en su patria: realismo y abstracción. Aunque experimentó con la segunda, terminó por enamorarse del barroco y sus valores: la austeridad, la manifestación del dolor, el gozo, la fastuosidad y la teatralización de las composiciones. Nos llama la atención el proyecto más ambicioso de su carrera que se exhibió en el Museo del Palacio de Bellas Artes de Méjico en 1985, Homenaje a Jan van Eyck: variaciones sobre el matrimonio Arnolfini. En este caso hace apropiacionismo en serie: de un mismo cuadro salen 20 reinterpretaciones distintas. Benjamín utiliza la técnica del temple y la combinación con el óleo para dar una nueva significación a la obra original al introducir elementos actuales, e inventa los fotogramas más significativos de la vida matrimonial de los Arnolfini. Nos deja inmiscuirnos en la posible realidad más allá del momento de las nupcias, haciendo una recreación de la escena posterior a la representada en el cuadro. Benjamín nos ilustra lo que les podría pasar a estos dos seres encerrados en las convenciones y símbolos de la época, y les da ese tiempo para que podamos ver otro tipo de relación y acciones entre la pareja. Las variaciones transcurren dentro de esa alcoba en una trama obsesiva en la que el placer y el dolor son la temática principal. Así pues, vemos a este matrimonio en todo tipo de situaciones sadomasoquistas y fetichistas, con el protagonismo del tatuaje en los cuerpos consigue que los situemos en la actualidad. Benjamín defiende la conexión indisoluble del arte clásico con el moderno, lo que en este caso nos sirve para 
enaltecer al apropiacionismo: "El arte no tiene tiempo, no es antiguo ni moderno, sino que transcurre y va cambiando. Tendrá sus variaciones, pero en realidad lo que estamos pintando ahora es lo mismo que lo que estaban pintando entonces, inclusive los temas." (Milenio, 2013, $\min 4.40)$.

Eisen Bernard Bernardo (1986), nacido en Vietnam, es un diseñador gráfico que sin haber estudiado una carrera artística se ha hecho un hueco en el arte digital con sus ingeniosas creaciones. Empezó en el 2008 a producir este tipo de arte de forma autodidacta: "No tengo formación artística específica, pero formo parte de la era digital donde la gente se expresa libremente utilizando diferentes formas de arte. El mundo del arte es un sector de élite, pero las redes sociales lo han democratizado y lo han hecho más accesible para todos." (OVH-SAS, 2019, párr. 1). Sus collages integran con maestría las imágenes teniendo en cuenta factores como las posturas de los personajes, el color de la composición y la ubicación lógica en la escena. Destacamos aquí el proyecto Mag+Art, en el que mezcla pinturas clásicas de autores muy relevantes como Boticelli, Klimt, Picasso, Jacques-Louis David, con portadas de revistas, tales como Life, Vanity Fair, Esquire y Rolling Stone. Portadas protagonizadas por personajes actuales de la política y sociedad, también conocidos por todos. Y consigue superponer la figura que aparece en la revista sobre el cuadro haciéndolo coincidir de manera exacta con el personaje original y cambiando su rostro, y con ello su identidad. Es como un intruso actual se hubiera metido en el cuadro, provocando una percepción sorprendente. Así la chica que nos mira en Un bar del Folies-Bergère ya no es la joven rubia con flequillo y gesto cabizbajo, sino la modelo Kate Moss. Bernardo sitúa dos contextos separados por siglos bajo la misma narración, y crea una lectura holística, según su intención de homenajear a las revistas como vinculo de la cultura popular. Con un planteamiento similar que conlleva la unión de imágenes que provienen de dos mundos diferentes, desarrolla el proyecto titulado Logo+Art. Bernardo combina la imagen de logotipos y marcas conocidas con las pinturas de siempre. Esta unión no es fortuita, sino que busca su relación a través del contenido de las imágenes, es decir del tema, aunque no de las claves estéticas. Asombra la cohesión que propone del logotipo del conejo de Playboy con la liebre de Durero, por poner un ejemplo. Nos lleva a una reflexión sobre lo individual que es la pintura como acto de creación personal, con lo colectivo que viene predeterminado por las marcas de consumo, lo corporativo.

El Equipo Crónica fue, en origen, la Estampa Popular Valenciana. Formado por Manuel Valdés (1942), Rafael Solbes (1940-1981) y Antonio Toledo (1940-1995). Apostaban por un arte realizado en equipo como rechazo a la individualidad artística, un arte que es crónica de una realidad que nos invitaban a cuestionar social y políticamente. Se enmarcan en el movimiento del Pop Art español, que ponen al servicio de la sátira, diferenciándose de la intrascendencia del Pop Art americano. En sus obras vemos como rescatan imágenes conocidas e introducen en ellas elementos totalmente ajenos a la composición, a la gama de color, anacrónicos y en discordia con la temática. Este intrusismo puede resultar en primera instancia un disparate, pero finalmente logran contextualizar esa amalgama de información dispar bajo un mismo formato incorporando nuevas lecturas políticas, críticas y sarcásticas. Es el caso de obras tales como El intruso o la serigrafía Guernica donde utilizan fórmulas artísticas del Pop Art anteponiendo el dramatismo y la violencia de lo bélico con el humor y la fantasía de los tebeos.

\section{CONCLUSIONES}

El arte, como cualquier ciencia, ha de buscar sostén en resultados, referentes y lecturas ya descubiertos para garantizar su evolución. Solo así se estimula y progresa, encontrando nuevas visiones a partir de lo ya inventado. Este axioma da respuesta a la licitud de recurrir a algo ya difundido, como acicate para crear nuevas conclusiones artísticas.

Todavía cobra más significado si nos situamos en las sociedades actuales, en las que una pléyade de imágenes iconográficas se ha instalado en nuestra memoria, por lo que el apropiacionismo o su nuevo uso pueden ser un recurso de respuesta esta saturación de imágenes globales. En un contexto de sobreexposición (hartazgo de imágenes), nace la posibilidad del reciclaje visual, lo que nos obliga a la reutilización de lo ya existente para no seguir contaminando. Sin ser conscientes de ello, podríamos haber creado un vertedero de imágenes en paralelo a la sociedad de consumo para seguir almacenando y utilizando.

La apropiación se defiende como medio creador eficaz, por ser una herramienta visibilizadora, ya que consigue dotar de visibilidad extra a una imagen, porque confiere autoridad a algo conocido y registrado por la sociedad. El apropiacionismo requiere de un procedimiento de observación, análisis y recuperación del "desecho ocular". Por supuesto logra recalificar el arte y las imágenes que nos rodean que podrían haber quedado en el olvido.

El proceso creativo, utilizado en este caso por los artistas, precisa de un ordenamiento procesual bien establecido que se basa en: percibir, identificar, interpretar y significar. Con ello se consigue proyectar una nueva significación condicionada por la percepción actual que tenemos de la realidad. Se podría decir que es una suma de contenidos, en ocasiones con tintes de humor, irónicos o críticos que nos llegan a modo de guiños perceptivos.

Se trata de imágenes invisibles archivadas en nuestra razón, que se vuelven visibles y logramos recordar al menor indicio de ser representadas. Se materializan porque forman parte del imaginario colectivo, existen. Por otra parte, al ser contenidos universales, son capaces de llegar por igual a distintas culturas y franjas sociales. Desde aquí reivindicamos: licencia para copiar. 


\section{FUENTES REFERENCIALES}

Amón, S. (1977, julio 31). Historia del "collage" en forma de "collage". El País. Recuperado 11 febrero 2019 , de https://elpais.com/diario/1977/07/31/cultura/239148020 850215.html

Aznar, J.M. (2016, agosto 31). El genio roba. Huffpost. Recuperado 2 febrero 2019, de https://www.huffingtonpost.es/jose-maria-aznarauzmendi/el-genio-roba b $11758290 . h t m l$

Bernardo, E. B. (2014). Behance. Recuperado (2 febrero 2019) de: https://www.behance.net/eisenbernard

Campo, E. (2017, septiembre 3). El 'Velázquez' falsificador. El Español. Recuperado 3 febrero 2019 , de https://www.elespanol.com/reportajes/20170901/243476100 0.html

Costa, J. (1992). Imagen pública: Una ingeniería social. Madrid: Fundesco.

Esgueva, V. (2011). El signo tipográfico como herramienta aplicada al arte: Una aportación personal (Tesis doctoral). Universitat Politècnica de València, Valencia. Recuperado de https://riunet.upv.es/handle/10251/11005

Furió, D. (2014). Apropiacionismo de imágenes, found footage (artículo docente). Departamento de Escultura de la Universitat Politècnica de València, Valencia. Recuperado de https://riunet.upv.es/handle/10251/37019

Ghesquière, K. (2019). Kunzt Gallery. Recuperado de https://www.kunzt.gallery/ES/glosario/qu-es-el-apropiacionismo

González, J.F. (2018). Collage, apropiacionismo y propiedad intelectual. Visual: magazine de diseño, creatividad gráfica y comunicación. Recuperado de http://visual.gi/collage-apropiacionismo-y-propiedad-intelectual/

Judith decapitando a Holofernes. Artemisia Gentileschi. [Fotografía]. (s.f.). Recuperado de https://commons.wikimedia.org/wiki/File:Gentileschi Artemisia Judith Beheading Holofernes Naples.jpg

$\begin{array}{llllll}\text { Judith } & \text { y } & \text { Holofernes. } & \text { Caravaggio. } & \text { [Fotografía]. } & \text { (s.f.). }\end{array}$ https://commons.wikimedia.org/wiki/File:Caravaggio Judith Beheading Holofernes.jpg

Milenio. (2013, mayo 11). Benjamín Domínguez en el Milenio visto por el arte [Vídeo]. Recuperado de: https://www.youtube.com/watch?v=tLPIsPG4fdc

OVH-SAS. (2019). ClassArt. Recuperado 24 febrero 2019, de http://classart.ovh/en/eisen-bernard-bernardo/

Revista Leemas de Gandhi. (Productor). (2015, julio 29). El librero de Benjamín Domínguez [Vídeo]. Recuperado de https://www.youtube.com/watch?v=- o6sm9gMsc

Vila-Matas, E. (2002). El mal de Montano. Barcelona: Anagrama.

Wescher, H. (1980). La historia del collage: del cubismo a la actualidad. Barcelona: Gustavo Gili. 